Paweł Bąk

Rzeszów

\title{
WYBRANE ASPEKTY PRZEKŁADU AFORYZMÓW NA JĘZYK NIEMIECKI NA PRZYKŁADZIE MYŚLINIEUCZESANYCH STANISŁAWA JERZEGO LECA
}

Zarys treści. Przedmiotem rozważań jest problem tłumaczenia aforyzmów Stanisława Jerzego Leca w przekładzie Karla Dedeciusa na język niemiecki. W sposób deskryptywny omówiony zostaje przekład metafor i gier słownych. Metafora traktowana jest tutaj jako fenomen języka literackiego, jednak - z uwagi na specyfikę języka tekstów - także jako zjawisko ogólnojęzykowe.

A foryzm jest ze względu na swe walory niewątpliwie tekstem artystycznym, na co zwraca uwagę wielu badaczy ${ }^{1}$. Jako jego główne cechy wymienia się między innymi: rzucającą się w oczy lapidarność, poznawczy charakter wyrażanej myśli², wieloznaczność, znaczenie formy tekstu, umieszczoną w końcowej części tekstu puentę, unikanie wydawania sądów wprost, zmuszanie czytelnika do wysiłku intelektualnego, tzn. do poszukiwania morału przemyconego w tekście. Z wymienionych powyżej cech wynika szczególny charakter aforyzmu jako obiektu transferu na język obcy. W kontekście badań nad przekładem na ów fakt zwróciło uwagę niewielu autorów. Są wśród nich S. Barańczak (2004: 122-130) oraz M. Krysztofiak i S. H. Kaszyński (2004: 382-389). Obok specyficznej dla aforyzmu metafo-

${ }^{1}$ M.in. M. Balowski (1992 i 1999), K. Orzechowski (1984), S. Barańczak (2004) oraz M. Krysztofiak i S. H. Kaszyński (2004).

2 Aforyzmy stanowią sformułowane artystycznie diagnozy poznawcze (Krysztofiak, Kaszyński 2004: 382). 
ryki wspomniane właściwości aforyzmów traktować można jako ich cechy gatunkowe. Przedstawienie trudności zachowania ich w przekładzie na język obcy stało się zamysłem niniejszych rozważań. Przybliżenie wybranych aspektów specyfiki przekładu zaprezentowano na przykładzie Myśli nieuczesanych S. J. Leca, będących obiektem transferu na język niemiecki w tłumaczeniu Karla Dedeciusa - tłumacza i uznanego ambasadora polskiej kultury w Niemczech.

Obok wspomnianych cech do elementów języka aforyzmu należy wbrew pozorom także i metaforyczność. Na fakt ten zwrócił uwagę m.in. Mieczysław Balowski (1992: 43-44; 1999: 35). Chodzi tu przede wszystkim nie o kwieciste przenośnie poetyckie, lecz zwroty określane przez badaczy mianem metafor zleksykalizowanych oraz konwencjonalnych, występujących także w tekstach nieliterackich i komunikacji codziennej ${ }^{3}$. Stanowią one w ostatnich dziesięcioleciach przedmiot dociekań m.in. przedstawicieli badań kognitywnych (Por. Lakoff/Johnson 1980). Występujące u Leca metafory niemal zawsze służą grze językowej. Możliwa jest tu ona dzięki odwołaniu się do dosłownego znaczenia zwrotów przenośnych przez poddanie ich procesowi demetaforyzacji. Jest to z jednej strony ciekawy zabieg językowy, z drugiej zaś zjawisko uświadamiające konieczność rozróżniania dwóch rodzajów mowy - metaforycznej i dosłownej, mimo zrezygnowania przez wielu współczesnych badaczy z owego rozgraniczenia.

Przekład stanowi wyzwanie wymagające od tłumacza podejmowania niełatwych decyzji dotyczących strategii i konkretnych technik translatorskich. Przy omawianiu możliwości przekładu aforyzmów pomocne okazuje się poszerzenie perspektywy badawczej i integracja dwóch dziedzin - perspektywy lingwistycznej i literaturoznawczej, postulowana w pracach badaczy przekładu, na przykład przez M. Snell-Hornby (1988) oraz K. Lipińskiego (1989).

${ }^{3}$ Stanisław Jerzy Lec daleki jest od (nad)używania metafor poetyckich; nie trudno jednak przy zastosowaniu instrumentarium językoznawczego odkrywać w jego utworach wśród figur językowych metafory zleksykalizowane, konwencjonalne, które każą postawić pytanie o możliwość adekwatnego oddania stopnia zleksykalizowania zwrotu przenośnego, poddawanego nierzadko procesowi demetaforyzacji.

${ }^{4}$ By sprostać wyzwaniu przedstawienia choćby samej metafory, niezbędne jest poszerzenie perspektywy w spojrzeniu na język i metaforykę. Pomocna okazuje się tu m.in. orientacja w językoznawczym instrumentarium badawczym, ale i znajomość motywów literackich, do których nadzwyczaj chętnie uciekają się aforyści. Uwzględnienie aspektów metaforyki jako motywu literackiego włączył do dyskusji o metaforze Harald Weinrich (1976: 287). Teoria Lakoffa i Johnsona uwzględnia aspekt tzw. koherencji kulturowej, odwołując się jednak raczej do doświadczeń przestrzennych człowieka i jego orientacji w świecie. 
Okazuje się, że wśród Myśli nieuczesanych przełożonych przez Dedeciusa na język niemiecki można znaleźć utwory, których transfer zdaje się nie nastręczać tłumaczowi większych trudności. W pewnych przypadkach możliwy jest mianowicie przekład bezpośredni, dosłowny. Z uwagi na ową dosłowność pozwolę sobie nie omawiać tychże przypadków, poświęcając im więcej uwagi w innym kontekście. Mimo możliwych tu nieznacznych odchyleń od tekstów wyjściowych, spowodowanych różnicami w strukturach języków, nie zachodzi konieczność większej ingerencji w ogólny kształt aforyzmu. Zdarza się jednak, iż mimo pewnych podobieństw w metaforycznym postrzeganiu świata mamy do czynienia $\mathrm{z}$ różnicami $\mathrm{w}$ językowej realizacji owych wyobrażeń czy pojęć, co prowadzić może na przykład do naruszenia zasady lapidarności aforyzmu w języku docelowym. W takich przypadkach tekst zostaje rozbudowany: „Głowa do góry!” - rzekł kat zarzucajac stryczek (1998: 107) / "Kopf hoch” sagte der Henker, und warf ihm die Schlinge um den Hals ${ }^{5}$ (LvD1970: 10).

Rozszerzenie tekstu następuje w procesie przekładu, gdy struktury języka docelowego nie są w stanie wyrazić tej samej treści za pomocą analogicznego minimum słów.

Tłumaczenie aforyzmu Człowiek, Korona Stworzenia - cierniowa (L1998: 146) jako Der Mensch ist die Dornenkrone der Schöpfung (LvD1970: 85), jest przykładem innej modyfikacji, tzn. przesunięcia puenty. W języku niemieckim przeciwstawienie korony cierniom stało się kontaminacją dwóch motywów bilbijnych Schöpfung oraz Dornenkrone. Zachodzi tu transpozycja ${ }^{6}$. O ile w oryginale zaskakująca czytelnika przydawka (cierniowa) była ukoronowaniem tekstu, to w przekładzie motyw ten pojawia się już wcześniej jako człon złożenia Dornenkrone. Zmiana ta dotyczy oddziaływania całego aforyzmu, dającego się w oryginale określić mianem efektu „aha”. Użyty w przekładzie rzeczownik Schöpfung (stworzenie) nie jest już puentą. Utwór docelowy, będący sentencją o podobnym przesłaniu, nie kończy się równie zaskakująco. Obok rozbudowania aforyzmu jest to kolejna modyfikacja tekstu - transpozycja, która dotyka jednej z cech gatunkowych aforyzmu, tj. typowego dla tych tekstów (nie tylko autorstwa Leca) umieszczenia morału w końcowej części utworu.

${ }^{5} \mathrm{Na}$ ową parafrazę zwrócił uwagę S. Barańczak (2004: 122-130).

${ }^{6} \mathrm{Na}$ temat transpozycji por. J.-P. Vinay, J. Darbelnet (1958), J. Albrecht (1973) i późniejsze prace, np. M. Schreiber (1993). 
$\mathrm{Na}$ inną transpozycję obligatoryjną, czyli modyfikację tłumaczonego tekstu, skazany jest przekład innych utworów Leca. Należy do nich zdanie: Miał umysł otwarty, niestety na przestrzał (L1998: 105). Zleksykalizowana metafora otwarty umyst poddana zostaje demetaforyzacji. Odbywa się to pod wpływem zwrotu na przestrzał, umieszczonego także i tu „aforystycznie" - na końcu tekstu. Wyraz umyst skonfrontowany z brutalną dosłownością słów otwarty na przestrzał budzi drastyczne skojarzenia. Podobnie jak i w innych tekstach, za ich pomocą Stanisław Jerzy Lec porusza temat totalitaryzmów XX wieku. Przeciwstawienie: dosłowność - metaforyczność pojawia się także i w języku niemieckim, dzięki zastosowaniu przez tłumacza wyrażenia durch und durch. Jest ono synonimem określeń völlig bądź ganz und gar: Sein Verstand war offen. Leider durch und durch (LvD1996: 218). Zwrot może dopuszczać interpretację zbliżoną do wymowy tekstu polskojęzycznego, nie odnosi się jednak w pierwszej kolejności do konkretnych obiektów rzeczywistości pozajęzykowej, jak w oryginale. I tu możliwe są jednak obecne w oryginale asocjacje, np. skojarzenie z czasownikiem durchschießen.

Innego rodzaju wariację spotkamy natomiast w przykładzie: Żyjemy w epoce łupanego atomu (L1996: 214) / Wir leben im Zeitalter des gespaltenen Atoms! (LvD1996: 270). Z uwagi na nieuwzględnienie w języku niemieckim przeciwstawienia leksemów łupany oraz atom, rozwiązanie to należy raczej uznać za chybione. Epoka łupanego atomu to metaforyczne zestawienie niekompatybilnych elementów - kontaminacja określenia epoki kamienia łupanego (po niem. 'Paläolithikum', 'Altsteinzeit') z symbolem nowoczesności. Jest to oparta na kontraście gra słów, która może wyrażać powątpiewanie w postęp, jego zaprzeczenie, brak wiary w nowoczesność i w dobrodziejstwo wynalazków. Brak w języku docelowym określenia epoki posiadającego porównywalne człony (po niem. 'Paläolithikum' 'Altsteinzeit') skazuje aforyzm na niemożność wyrażenia owej negacji postępu czy degradacji nowoczesności do rangi epoki kamienia.

Przypadkami ocierającymi się o barierę nieprzetłumaczalności są trzy utwory, w których autor przekładu zmuszony jest do trudnych poszukiwań.

W tekście Pomyśl, zanim pomyślisz! (L1998: 80) w pierwszym akcie mowy (pomyśl) mamy do czynienia $\mathrm{z}$ wezwaniem do wysiłku intelektualnego. Użyty po raz drugi wyraz pomyśl można odebrać jako stosowany powszechnie czasownik poprzedzający wyrażaną opinię. Parafraza aforyzmu mogła- 
by zapewne brzmieć w następujący sposób: 'Pomyśl, zanim coś powiesz!’” Wykorzystanie w języku niemieckim analogicznej polisemii nie było możliwe; tłumacz sięga natomiast po istniejące $\mathrm{w}$ tym języku środki słowotwórcze (denken - bedenken). Zabieg ten pozbawia wprawdzie aforyzm powtórzenia leksemu (podaje on wręcz gotową interpretację znaczenia czasownika), ratuje jednak w dużym stopniu grę słowną. Rozwiązanie Bedenke, bevor du denkst (LvD1996: 49) daje się określić mianem kompensacji.

Przy odtwarzaniu kolejnego tekstu Zegar tyka. Wszystkich (L1998: 82) jako Die Uhr schlägt. Alle (LvD1996: 12) tłumacz nie starał się osiągnąć ekwiwalencji w obrębie semantyki słów przez zachowanie sensu tykać jako mówić per ty ${ }^{8}$. Usiłował uratować metafizyczną wymowę aforyzmu w inny sposób. U Dedeciusa brak dosłowności w przekazie poszczególnych sensów, zachowany zostaje jednak ten sam element asocjacji, podkreślony jeszcze nieco przez zastosowanie polisemii słowa schlagen. Nazywa ono z jednej strony bicie zegara, $\mathrm{z}$ drugiej zaś, w połączeniu z leksemem alle, wywołuje skojarzenie z mniej dyplomatycznym obchodzeniem się czasu z człowiekiem; ma tu zatem miejsce swoiste wzmocnienie wymowy sugerowanej przez Leca9.

Atrakcyjny pod względem formy żart pozwoliła stworzyć dwuznaczność leksemów w innym pozornie nieprzetłumaczalnym aforyzmie: Daj wyraz słowu! (L1998: 146). Samo zastąpienie wyjściowego zwrotu dać wyraz niemieckim Ausdruck geben nie umożliwiłoby odtworzenia podobnego kalamburu. Ponieważ polisemia, która w oryginale pozwoliła rozbić związek dać wyraz, nie mogła się tu pojawić, tłumacz zastosował ciekawy zabieg - zdecydował się na użycie łącznika pomiędzy członami derywatu Aus-druck, co bardziej sugeruje możliwość rozerwania owego związku w interpretacji: Gebt dem Wort Aus-Druck! (LvD1996: 346) ${ }^{10}$.

${ }^{7}$ Stanisław Jerzy Lec w wielu swych utworach daje się poznać jako osoba uczulona na językową niestaranność, pustosłowie, apelując o wydawanie wyważonych sądów. Lec nie jest też zwolennikiem używania górnolotnych sformułowań, stających się z czasem wyświechtanymi frazesami. Daje on temu wyraz w kilku swych aforyzmach, np. w: Na początku było Słowo - na końcu Frazes (L1998: 52) / Im Anfang war das Wort - am Ende die Phrase (LvD1996: 17). Por. także przypis 3.

${ }^{8}$ Wskazówkę precyzującą interpretację tykać jako mówić per ty zawdzięczam prof. K. Lipińskiemu.

${ }^{9}$ Por. Barańczak 2004: 127-128. Nie daje się tu również wykluczyć skojarzenia z wybijaniem ostatniej godziny / jemandem Schlägt die letzte Stunde.

${ }^{10}$ Nieuniknione są ponadto inne asocjacje dotyczące niemieckojęzycznego leksemu Druck. 
Kolejne trzy przykłady ukazują pewną tendencję tłumacza do ułatwienia czytelnikowi interpretacji. Bezpośredni przekaz treści, a jednocześnie pewne zubożenie tekstu stanowią kolejno: wprowadzenie dodatkowych elementów (innen oraz außen - w pierwszym z poniższych przykładów), intensyfikację wymowy ( $\mathrm{w}$ drugim aforyzmie) czy wreszcie podanie gotowej wręcz interpretacji (w ostatnim tekście), podczas gdy aforyzm niemalże per definitionem nie przekazuje treści wprost:

Żółw musi być aż tak twardy, bo jest aż tak miękki (L1998: 106).

Wer innen weich ist, muß außen hart sein: siehe Schildkröte (LvD1996: 368).

Z jego ust wychodzą najszlachetniejsze słowa. Dziwicie się im? (L1998: 103).

Seinem Mund entfliehen die edelsten Worte. Wundert das euch? (LvD1970: 40).

„Książka twój przyjaciel”. Trzeba ją najczęściej kupować (L1996: 175).

„Das Buch - dein Freund” - weil es käuflich ist? (LvD1996: 247).

Inne rozwiązanie stanowi substytucja, stosowana w obliczu groźby nieprzetłumaczalności. Zubaża ona tekst, gdyż pozbawia go wieloznaczności czy różnorakich asocjacji. Przykładem przełożonej w ten sposób Myśli nieuczesanej jest utwór: Czas robi swoje. A ty człowieku? (L1998: 53), w niemieckojęzycznym brzmieniu: Die Zeit schreitet voran. Und du, Mensch? (LvD1996: 40). Przez użycie elementu voranschreiten jako metafory rozwoju, motyw czasu stracił zdolność wywierania wpływu na (los) człowieka, co w języku polskim wyraża się w czasowniku robić.

Obok poszukiwań rozwiązań, do czego autor przekładu zmuszony jest różnicami pomiędzy strukturami języków, istotną rolę w przekładzie odgrywa inwencja tłumacza, dyktująca mu rozwiązania inne niż możliwy i z pozoru adekwatny przekład dosłowny. Jest to tzw. transpozycja fakultatywna.

Nie sposób w tym miejscu nie przytoczyć znanego aforyzmu Stanisława Jerzego Leca, chętnie cytowanego i analizowanego przez badaczy, skomentowanego zresztą przez samego Karla Dedeciusa w wywiadzie udzielonym niemieckiej stacji radiowej Norddeutscher Rundfunk: Sumienie miat czyste. Nie używane (L1998: 105) / Sein Gewissen war rein, er benutzte es nie (LvD1996: $105)^{11}$. I w tym przypadku autor ucieka się do ulubionego zabiegu przepla-

${ }^{11}$ Por. Karl Dedecius w wywiadzie Talk auf 4, NDR 4, 20.02.1998; Krupka 1976: 91. Więcej na ten temat: Krysztofiak, Kaszyński 2004: 386. 
tania dosłowności ze znaczeniem przenośnym ${ }^{12}$, na co zwrócił uwagę P. Krupka (1976: 97). Dotyczy to użycia atrybutu czyste, odnoszącego się do abstrakcyjnego pojęcia sumienie, odzyskującego jednak znaczenie verbum proprium w połączeniu ze zwrotem nie używane. Frazę cechuje struktura eksponująca sumienie, które w zdaniu nie występuje jako novum, remat, lecz jest tematem wypowiedzenia ${ }^{13}$. Kolejność Sumienie miat czyste każe dostrzegać w dopełnieniu sumienie element łączący zdanie $\mathrm{z}$ wypowiedzią poprzedzającą aforyzm, której tu de facto brak. Stwarza to wrażenia istnienia pewnego szerszego kontekstu bądź sugeruje osadzenie go w sytuacji, gdzie o sumieniu była już mowa. We wspomnianym wywiadzie autor przekładu określił własne rozwiązanie jako przykład na uniknięcie niepoetyckiej dosłowności. Tak rozumiane wierne tłumaczenie (jako Er hatte ein reines Gewissen, ein unbenutztes) po namyśle i modyfikacjach tłumacz odrzucił. Zrobiłby zapewne to także z zaproponowanym przez P. Krupkę tłumaczeniem jako Sein Gewissen war rein. Er hatte es nie benutzt (Krupka 1976: 91). Ostateczna wersja przekładu opiera się podwójnej transpozycji. Z jednej strony na wprowadzeniu orzeczenia imiennego (Sein Gewissen war rein) w miejsce 'Er hatte ein reines Gewissen'. Wynika to z konieczności zachowania szyku eksponującego wyraz sumienie ('Gewissen'). Drugą modyfikacją, na którą tłumacz zdecydował się z własnej inicjatywy, mając na uwadze walory estetyczne, jest oddanie równoważnika zdania Nie używane za pomocą frazy: Er benutzte es nie. Transpozycja ta nie jest podyktowana różnicami między strukturami języków; jest ona wyrazem kreatywności tłumacza, traktującego siebie jako (współ)autora tekstu.

Najprawdopodobniej z tych samych pobudek z dużą swobodą tłumaczy on kolejne Myśli nieuczesane, osiągając niekiedy efekt większej zwięzłości formy niż w języku wyjściowym, np.: Po stracie zębów podobno większa swoboda języka (L1998: 103), jako Zahnlose haben größere Zungenfreiheit (LvD1970: 49, LvD1996: 154).

Przy uwzględnieniu głównych cech tekstów należy stwierdzić, iż Karl Dedecius starał się zachować specyfikę utworów, choć w przypadku lakoniczności sformułowań aforyzmu nie zawsze okazuje się to możliwe. Wyni-

${ }^{12}$ Możliwy jest w interpretacji szereg innych skojarzeń, wynikających z możliwości użycia przymiotnika czyste w połączeniu z pojęciami abstrakcyjnymi oraz wyrazami o znaczeniu konkretnym.

${ }^{13}$ Neutralny szyk zdania brzmiałby Miał czyste sumienie. Odnośnie do różnic w strukturze tematyczno-rematycznej zdania polskiego i niemieckiego por. Deutsch-polnische kontrastive Grammatik (1999: 527-531). 
ka to $\mathrm{z}$ różnic między systemami obydwu języków. Jednak pewne modyfikacje są rezultatem świadomych decyzji translatorskich. Obok uciekania się z konieczności do konstrukcji odbiegających od struktur języka oryginału, zwanego w literaturze transpozycją obligatoryjną, podkreślić należy istnienie w przekładzie licznych przypadków transpozycji fakultatywnej, tzn. przekładu kreatywnego, o znamionach tworzenia nowego wręcz teksu artystycznego. Odczuwalne są w tłumaczeniu modyfikacje dotyczące cech gatunkowych. W przypadku przekładu utworów potwierdzić należy znaczne rozbieżności istniejące pomiędzy oryginałem a przekładem stwierdzone już przez badaczy, szczególnie przez Marię Krysztofiak i Stefana H. Kaszyńskiego (2004: 382-389). Dużą swobodę w warsztacie tłumacza uważać można za bardziej udaną niż dosłowny przekład tych tekstów, który nie zawsze pozwoli oddać ich walory artystyczne. Pewne straty i zubożenie języka aforyzmów dotyczyć mogą sekundarnych cech tekstów, warstwy asocjacji, tzn. możliwości wywołania u odbiorcy wielu skojarzeń równocześnie. Niekiedy tłumacz ulega pokusie pozbawienia czytelnika ciężaru interpretacji i bierze to zadanie na swe barki. Odnośnie do metaforyki stwierdzić należy, że mimo braku konieczności zastępowania metafor innymi zwrotami z powodu nacechowania kulturowego, występujące w żartach słownych Myśli nieuczesanych przenośnie skutecznie zobowiązywały Dedeciusa do zachowania metaforyczności w języku niemieckim.

\section{Literatura}

\section{Literatura źródłowa}

Lec, S. J. (1996): Myśli nieuczesane odczytane z notesów i serwetek po trzydziestu latach, Warszawa. (L1996)

Lec, S. J. (1998): Widziałem szkic do nicości. Wiersze, aforyzmy, prozy, fraszki, Kraków. (L1998)

Lec, S. J. $\left(1970^{4}\right)$ : Letzte unfrisierte Gedanken. Aphorismen, München. (LvD1970)

Lec, S. J. (19963): Sämtliche unfrisierte Gedanken: dazu Prosa und Gedichte, Wien. (LvD1996) 


\section{Literatura cytowana}

Albrecht, J., 1973, Linguistik und Übersetzung, Tübingen.

Balowski, M., 1992, Struktura językowa aforyzmów (na materiale polskim i czeskim), Opole.

Balowski, M., 1999, „O tak zwanej literaturze aforystycznej, czyli aforyzm, sentencja, maksyma, złota myśl...”, [w:] Rozprawy Komisji Językowej XXV, red. J. Cygan, J. Miodek, Wrocław, s. 33-40.

Barańczak, S., 2004, Ocalone w tłumaczeniu, Kraków.

Bąk, P., 2005, „Zur Transposition in der Wiedergabe metaphorischer Syntagmen, [w:] M. Wierzbicka i in., Moderne Deutsche Texte, Frankfurt/M. $\mathrm{i}$ in., s. 67-79.

Duden, 2001, Duden - Deutsches Universalwörterbuch, Mannheim-Leipzig-Zürich-Wien.

Debatin, B., 1995, Die Rationalität der Metapher: Eine sprachphilosophische und kommunikationstheoretische Untersuchung, Berlin-New York.

Engel, U. i in. (red.), 1999, Deutsch-polnische kontrastive Grammatik, Heidelberg.

Krupka, P., 1976, Der polnische Aphorismus. Die „Unfriesierten Gedanken“von Stanisław Jerzy Lec und ihr Platz in der polnischen Aphoristik, München.

Krysztofiak, M., Kaszyński, S. H., 2004, „O sposobach tłumaczenia aforyzmów”, [w:] Werte und Wertungen: Sprach-, litertur- und kulturwissenschaftliche Skizzen und Stellungnahmen. Festschrift für Eueniusz Tomiczek, red. I. Bartoszewicz i in., Wrocław, s. 382-389.

Lakoff, G., Johnson, M., 1980, Metaphors We live by, Chicago-London.

Lipiński, K., 1989, „Über die Sonderstellung der literarischen Übersetzung”, [w:] Studien zur kontrastiven Linguistik und literarischen Übersetzung, red. A. Kątny, Frankfurt/M. i in., s. 211-220.

NDR 4. Interview mit Karl Dedecius „Talk auf 4” audycja z dnia 20.02.1998.

Orzechowski, K. (red.), 1984, Żądło i miód mądrości. Antologia aforyzmu polskiego, Wrocław-Warszawa-Kraków.

Schreiber, M., 1993, Übersetzung und Bearbeitung. Zur Differenzierung und Abgrenzung des Übersetzungsbegriffs, Tübingen.

Snell-Hornby, M. (red.), 1988, Translation Studies. An integrated approach, Amsterdam-Philadelphia.

Vinay J.-P., Darbelnet, J., 1958, Stylistique comparée du français et de l'anglais. Méthode de traduction, Paris.

Weinrich, H., 1976, Sprache in Texten, Stuttgart. 


\section{On translation of aphorisms exemplified by some German translations of Stanisław Jerzy Lec's aphorisms chosen from his Myśli nieuczesane}

(summary)

The paper outlines the problem of German translation of some aphorisms by Stanisław Jerzy Lec rendered by Karl Dedecius. The study focuses mainly on aphorisms referring to dead as well as to lexical metaphors and puns. The concept of metaphor is in the paper recognized not only as a phenomenon of the language or literature but also as a phenomenon of general linguistics. Moreover, the author analyses some remarkable strategies applied by Dedecius in order to create analogous puns in the target language.

As a result of the differences between Polish and German, the translator often changes the form of the original aphorisms. Such changes are usually defined as obligatory transposition. Karl Dedecius does not translate literally and he often employs his own interpretations or comments to reach the effect of conciseness of the text in the target language. Many of the modifications are the effect of conscious decisions taken by the translator. Dedecius's creative translation is based on facultative transposition. Such a translation conveys more true sense of the original text than a literal one.

Dedecius also succeeds in rendering Lec's puns into German. However, the translator sometimes tends to provide direct interpretations, whereas the original aphorisms make the reader search for their meaning and interpretation. 